\title{
Polysaccharide utilization loci of North Sea Flavobacteriia as basis for using SusC/D-protein expression for predicting major phytoplankton glycans
}

\author{
Lennart Kappelmann ${ }^{1} \cdot$ Karen Krüger $^{1} \cdot$ Jan-Hendrik Hehemann $^{1,2} \cdot$ Jens Harder $^{1} \cdot$ Stephanie Markert $^{3,4}$. \\ Frank Unfried $\mathbb{1}^{3,4} \cdot$ Dörte Becher $^{5} \cdot$ Nicole Shapiro $^{6} \cdot$ Thomas Schweder $\mathbb{C}^{3,4} \cdot$ Rudolf I. Amann $^{1} \cdot$ Hanno Teeling ${ }^{1}$
}

Received: 15 February 2018 / Revised: 17 June 2018 / Accepted: 30 June 2018 / Published online: 15 August 2018

(c) The Author(s) 2018. This article is published with open access

\begin{abstract}
Marine algae convert a substantial fraction of fixed carbon dioxide into various polysaccharides. Flavobacteriia that are specialized on algal polysaccharide degradation feature genomic clusters termed polysaccharide utilization loci (PULs). As knowledge on extant PUL diversity is sparse, we sequenced the genomes of 53 North Sea Flavobacteriia and obtained 400 PULs. Bioinformatic PUL annotations suggest usage of a large array of polysaccharides, including laminarin, $\alpha$-glucans, and alginate as well as mannose-, fucose-, and xylose-rich substrates. Many of the PULs exhibit new genetic architectures and suggest substrates rarely described for marine environments. The isolates' PUL repertoires often differed considerably within genera, corroborating ecological niche-associated glycan partitioning. Polysaccharide uptake in Flavobacteriia is mediated by SusCD-like transporter complexes. Respective protein trees revealed clustering according to polysaccharide specificities predicted by PUL annotations. Using the trees, we analyzed expression of SusC/D homologs in multiyear phytoplankton bloom-associated metaproteomes and found indications for profound changes in microbial utilization of laminarin, $\alpha$ glucans, $\beta$-mannan, and sulfated xylan. We hence suggest the suitability of SusC/D-like transporter protein expression within heterotrophic bacteria as a proxy for the temporal utilization of discrete polysaccharides.
\end{abstract}

\section{Introduction}

Half of global net primary production is oceanic and carried out mostly by small, unicellular phytoplankton such as diatoms [1]. Polysaccharides account for up to $50 \%$ of algal biomass [2] and can be found as intracellular energy storage compounds, as structural components of their cell walls [3], or as secreted extracellular transparent exopolymeric substances [4]. They can be composed of different cyclic sugar monomers linked by either $\alpha$ - or $\beta$-glycosidic bonds at

Electronic supplementary material The online version of this article (https://doi.org/10.1038/s41396-018-0242-6) contains supplementary material, which is available to authorized users.

Thomas Schweder

schweder@uni-greifswald.de

$\triangle$ Rudolf I. Amann

ramann@mpi-bremen.de

$\triangle$ Hanno Teeling

hteeling@mpi-bremen.de

Extended author information available on the last page of the article. different positions and can be substituted by different moieties (e.g., sulfate, methyl, or acetyl groups), making them the most structurally diverse macromolecules on Earth [5].

Many members of the bacterial phylum Bacteroidetes, including marine representatives of the class Flavobacteriia, are specialized on polysaccharide degradation. They feature distinct polysaccharide utilization loci (PULs, [6]), i.e., operons or regulons that encode the protein machinery for binding, degradation and uptake of a type or class of polysaccharides. Polysaccharides are initially bound by outer membrane proteins and cleaved by endo-active enzymes into oligosaccharides suitable for transport through the outer membrane. Oligosaccharides are bound at the interface of SusCD complexes. SusD-like proteins are extracellular lipoproteins and SusC-like proteins constitute integral membrane beta-barrels termed TonB-dependent transporters (TBDTs). Glenwright et al. [7] showed that these two proteins form a 'pedal bin' complex in Bacteroides thetaiotaomicron, with SusD acting as a lid on top of the SusC-like TBDT. Upon binding of a ligand, the SusD lid closes and conformational changes lead to substrate 
release into the periplasm. Here, further saccharification to sugar monomers takes place that are taken up into the cytoplasm via dedicated transporters.

Besides the characteristic susCD-like gene pair, Bacteroidetes PULs contain various substrate-specific carbohydrate-active enzymes (CAZymes), such as glycoside hydrolases (GHs), polysaccharide lyases (PLs), carbohydrate esterases (CEs), carbohydrate-binding modules (CBMs), and proteins with auxiliary functions. PULs of human gut Bacteroidetes and their capacity to degrade various land plant polysaccharides have been thoroughly investigated (e.g., ref. [8]), but knowledge on marine polysaccharide degradation is sparse. Many polysaccharides in marine algae differ from those in land plants. Green macroalgae contain ulvans, red macroalgae contain agars, carrageenans and porphyrans, brown algae contain alginates, fucans and laminarin, and diatom microalgae contain chrysolaminarin and sulfated mannans, all of which are presumably absent in land plants [9]. Likewise, many algae feature anionic, sulfated polysaccharides that require sulfatases for degradation.

A systematic inventory of the structural diversity of algal polysaccharides has not yet been achieved. We do not have a good understanding of the associated diversity of PULs in marine Bacteroidetes. Also only few PULs have so far been linked to their polysaccharide substrate. Examples include an agar/porphyran-specific PUL [10] that human gut Bacteroidetes acquired from marine counterparts [11], an alginate-specific PUL in Zobellia galactanivorans DsiJ ${ }^{\mathrm{T}}$ [12], alginate- and laminarin-specific PULs in Gramella forsetii KT0803 [13], a similar laminarin-specific PUL in Polaribacter sp. Hel1_33_49 [14], and a complex carrageenan degradation regulon in $Z$. galactanivorans $\mathrm{DsiJ}^{\mathrm{T}}$ [15]. Few overarching comparative genomic studies exist $[14,16]$, focusing largely on overall CAZyme repertoires.

Pioneering studies on structural elucidation of polysaccharides from microalgae were performed [17, 18], but precise microalgal polysaccharide structures remain mostly unresolved (for review, see ref. [4]), because they require sophisticated methods [19]. PUL analysis of heterotrophic bacteria co-occurring with phytoplankton could serve as an alternative starting point to advance insight into the structures of marine polysaccharides and to understand their microbial decomposition.

Here we present a comparative analysis of PULs from 53 newly sequenced Flavobacteriia isolated from the German Bight, comprising a total of 400 manually determined PULs. Based on these data we investigated whether SusCand SusD-like sequences can be linked to distinct predicted polysaccharides. Using environmental metaproteome data we show how SusC/D homolog expression may be used to assess the presence of marine polysaccharides during North Sea spring blooms.

\section{Materials and methods}

\section{Isolation and sequencing of North Sea Flavobacteriia}

Flavobacteriia were sampled at the North Sea Islands Helgoland and Sylt as described previously ([20, 21], Supplementary Table S1). Also included were the previously sequenced Gramella forsetii KT0803 [22], Polaribacter spp. Hel1_33_49 and Hel1_85 [14], and the Formosa spp. Hel1_33_131 and Hel3_A1_48. The remaining 48 genomes were sequenced at the Department of Energy Joint Genome Institute (DOE-JGI, Walnut Creek, CA, USA) in the framework of the Community Sequencing Project No. 998 COGITO (Coastal Microbe Genomic and Taxonomic Observatory). Forty genomes were sequenced using the PacBio RSII platform exclusively, whereas eight isolates were sequenced using a combination of Illumina HiSeq 2000/2500 and PacBio RSII. All these genomes are GOLD certified at level 3 (improved high-quality draft) and are publicly available at the DOE-JGI Genomes OnLine Database (GOLD, [23]) under the Study ID Gs0000079.

\section{Gene and PUL annotation}

Initial annotations of the genomes of Polaribacter spp. Hel1_44_49 and Hel1_85 and Formosa spp. Hel1_33_131 and Hel3_A1_48 were performed using the RAST annotation system [24]. All other genomes were annotated using the DOE-JGI Microbial Annotation Pipeline (MGAP, [25]). These annotations were subsequently imported into a GenDB v2.2 annotation system [26] for refinement and additional annotations based on similarity searches against multiple databases as described previously [27].

SusC- and SusD-like proteins were annotated by the DOE-JGI MGAP, which uses the TIGRfam model TIGR04056 to detect SusC-like proteins and the Pfam models 12741,12771 , and 14322 to detect SusD-like proteins. CAZymes were annotated based on HMMer searches against the Pfam v25 [28] and dbCAN 3.0 [29] databases and BLASTp searches [30] against the CAZy database [31]. CAZymes were annotated only as such when at least two of the database searches were positive based on family-specific cutoff criteria that were described previously [32]. Selected sulfatases were annotated using the SulfAtlas database v1.0 [33]. Peptidases were annotated using BLASTp searches against the MEROPS 9.13 database [34] using the default settings of $\mathrm{E} \leq 10^{-4}$.

PULs were manually detected based on the presence of CAZyme clusters, which in most cases also featured co-occurring susCD-like gene pairs as previously suggested [6]. In some cases, the sequence similarity of a TBDT was too low to be considered SusC-like, no SusD homolog was 
present or the entire susCD-like gene tandem was missing. These operons were still counted as PULs and are regarded as incomplete subtypes [35].

\section{Gene expression analyses of Flavobacteriia-rich North Sea bacterioplankton using metaproteomics}

During spring phytoplankton blooms of 2009 to 2012, 14 surface seawater biomass samples were collected at the long-term ecological research station 'Kabeltonne' $\left(54^{\circ}\right.$ $\left.11.3^{\prime} \mathrm{N}, 7^{\circ} 54.0^{\prime} \mathrm{E}\right)$ off the German North Sea island Helgoland as previously described in detail $[32,36]$. Biomass was collected on $0.2 \mu \mathrm{m}$ pore sized filters after prefiltration with 10 and $3 \mu \mathrm{m}$ pore sized filters. Metagenome sequencing was done using the 454 FLX Ti platform for 2009 and the Illumina HiSeq 2000 platform for 2010 to 2012 samples [32].

Corresponding metaproteome analyses were performed from biomass obtained from the same water samples. Protein extraction from $0.2 \mu \mathrm{m}$ filtered bacterioplankton biomass and separation was carried out as described previously [36] with the modification that gel lanes were cut into 10 equal pieces prior to tryptic digestion $(1 \mu \mathrm{g} / \mathrm{ml}$, Promega, Madison WI, USA) and subsequent mass spectrometric detection in an LTQ Orbitrap Velos mass spectrometer (Thermo Fisher, Bremen, Germany). The mass spectrometry proteomics data have been deposited to the ProteomeXchange Consortium via the PRIDE partner repository [37]; data set identifiers: PXD008238, 10.6019/ PXD008238.

Mass spectrometric data were analyzed using Sequest v27r11 (Thermo Fisher Scientific, San Jose, CA, USA). Searches were carried out against a forward-decoy database of all proteins from all metagenome samples combined. This non-redundant database was constructed from all predicted protein-coding genes of all metagenomes $(6,194,278$ sequences) using the uclust option of USEARCH v6.1.544 [38]; options: cluster_fast; nucleotide identity 0.99 ; maxhits 5; maxrejects 30 ) and contained $3,212,324$ sequences. Common laboratory contaminants were included in all databases. Technical duplicates of each sample were searched together (including all 20 subsamples) to obtain averaged spectral counts. Validation of protein- and peptide identifications was performed with Scaffold v4 (Proteome Software Inc, Portland, OR, USA) using the parameters previously described [36], and normalized spectral abundance factors (\%NSAF) were calculated [39] to allow for semi-quantitative analyses (Supplementary Table S2). The NSAF quantitation measure is commonly used in non-gel-based label-free shotgun proteomics. In brief, a \%NSAF of 1 corresponds to $1 \%$ of all mass-adjusted spectral count data in a given proteomic experiment.

\section{SusC/D homolog tree reconstruction}

We constructed trees from SusC- and SusD-like protein sequences of the isolates' PULs (SusC: 369; SusD: 361). Sequences were aligned using MAFFT v7.017 [40] using the G-INS-i algorithm and BLOSUM62 matrix with default gap open penalty (1.53) and offset (0.123) values. Maximum-likelihood trees were constructed using FastTree 2.1.5 [41] with default settings.

\section{Results}

\section{High genomic and phylogenetic diversity in isolated marine Flavobacteriia}

The 53 flavobacterial isolates cover a broad range of the Flavobacteriia class within the phylogenetic tree based on full-length 16S rRNA genes (Fig. 1). The strains fall into several clusters that can be linked to characteristic genomic features (Supplementary Table S1). Genome sizes ranged from 2.02 Mbp (Formosa sp. Hel3_A1_48) to $5.98 \mathrm{Mbp}$ (Aquimarina sp. MAR_2010_214), with an average of 3.83 Mbp. One of the clusters was dominated by isolates obtained from the retentates of seawater filtered through 20 $\mu \mathrm{m}$ particle nets ( 8 out of 12 ; Fig. 1; Supplementary Table S1). These species feature mostly larger genomes (average $4.5 \mathrm{Mbp}$ ) and are likely associated with microalgae. Forty-seven of the 53 strains have two to four $16 \mathrm{~S}$ rRNA operons, with the notable exception of the three Tenacibaculum strains possessing six (strains MAR_2009_124 and MAR_2010_205) and seven (strain MAR_2010_89), respectively.

The capacity of the isolates to degrade polysaccharides varied widely as indicated by the number of degradative CAZymes per Mbp and predicted PULs per genome. On average, we identified 7.5 PULs per genome and 55 degradative CAZymes (Supplementary Table S1). Strains of the putative microalgae-associated cluster differed with on average 83.3 degradative CAZymes, almost twice as many PULs per genome (14.2) and many sulfatase genes, indicating an extended capacity for the degradation of sulfated polysaccharides (average of 28.2 sulfatases, with a maximum of 95 sulfatases in Zobellia amurskyensis MAR_2009_138). The other strains had an average of 46.8 degradative CAZymes and 5.5 PULs. Eleven isolates possessed less than three PULs, contained few $(\leq 3)$ or no sulfatases and were exclusively isolated from surface seawater or pore water. They likely target rather simple, nonsulfated polysaccharides and peptides. This strategy is emphasized by their high peptidase:CAZyme ratio of 1.81 , compared with an average ratio of 0.95 for isolates with $>$ 10 PULs. Still it is noteworthy that numbers of PULs and 


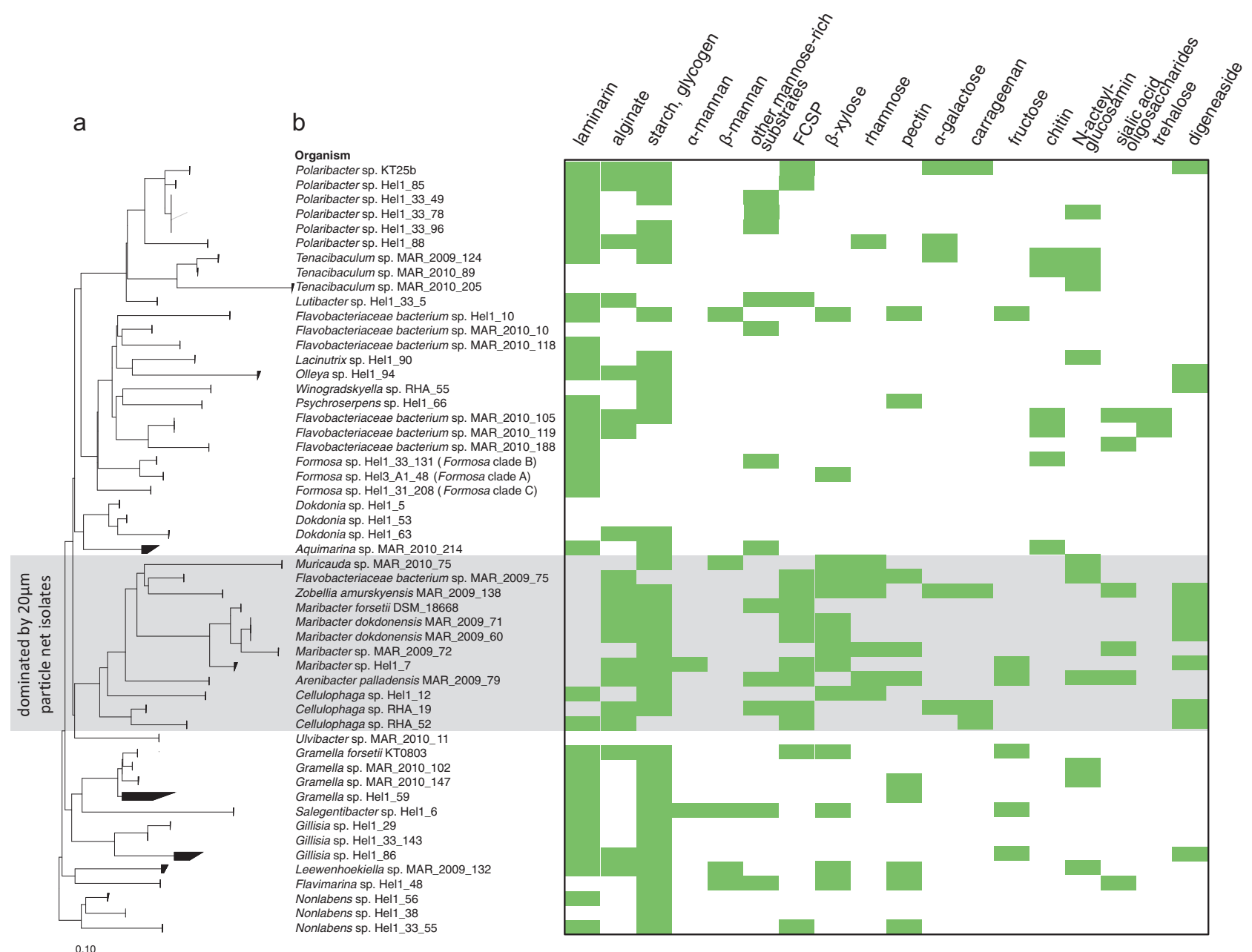

Fig. 1 a Maximum-likelihood tree of 53 North Sea Flavobacteriia isolates based on full-length $16 \mathrm{~S}$ rRNA gene sequences. Scale bar: 10 nucleotide substitutions per 100 nucleotides. b Predicted degradation capacities of polysaccharide classes based on PUL-associated CAZyme annotations

degradative CAZymes varied considerably, even within isolates of the same genus.

\section{Putative substrate specificities}

The 53 genomes revealed a wide range of as yet undescribed PULs. In total, 400 PULs were annotated, 259 of which could be linked to either dedicated polysaccharides or polysaccharide classes by in-depth annotations (Supplementary Table S3).

\section{Known and putative new laminarin PULs}

Laminarins are $\beta-1,3$-linked glucans that are abundant as they act as storage compounds in brown algae and diatoms (both Stramenopiles). Forty-six PULs $(\sim 12 \%)$ were predicted to be involved in laminarin degradation, featuring four variants (Fig. 2): Variant A is a highly conserved, short
PUL containing one predicted GH3 $\beta$-1,3-glucosidase framed by two predicted GH16 $\beta-1,3(4)$-glucanases (Fig. 2a). This arrangement was first described in Gramella forsetii KT0803 and shown to be upregulated by laminarin [13]. Two distinct GH16 laminarinases have been studied in Z. galactanivorans DsiJ $^{\mathrm{T}}$, which are endo-active [42, 43]. For this species, it has been speculated that a cell surfaceassociated GH16 glucanase cleaves branched laminarin polysaccharides into oligosaccharides [43], which can be transported through the SusC-like TBDT into the periplasm. Here, the GH3 $\beta$-1,3-glucosidase may further cleave off glucose units [44], which are imported into the cytoplasm.

Variant B is a larger, more variable PUL (Fig. 2b). It shares homology with a PUL in Polaribacter sp. Hel1_33_49 that can be induced by laminarin [14]. This PUL additionally features a predicted GH30 exo- $\beta-1,6-$ glucanase and at least two GH17 $\beta$-1,3-glucan hydrolases with predicted endo- and exo-activities, respectively. The 


\section{Laminarin}

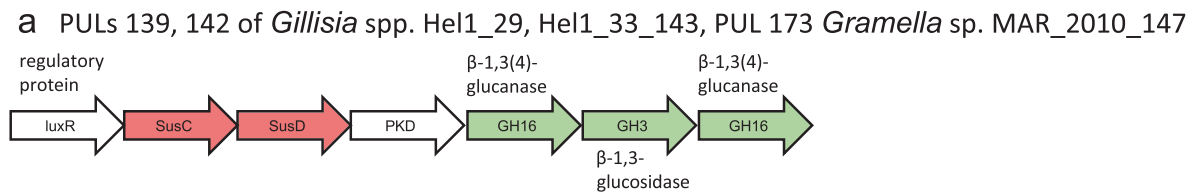

b PULs 291, 297, 299 of Polaribacter spp. Hel1_33_49, Hel1_33_78, and Hel1_33_96

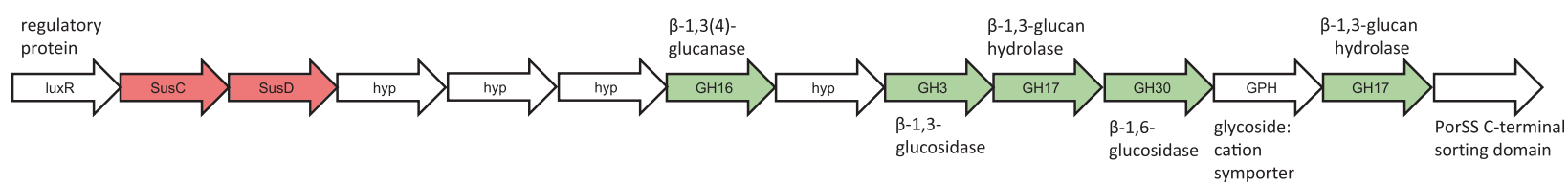

C PUL 133 of Formosa sp. Hel3_A1_48, PULs 288, 293, 301 of Polaribacter spp. Hel1_33_49, Hel1_33_78, and Hel1_33_96

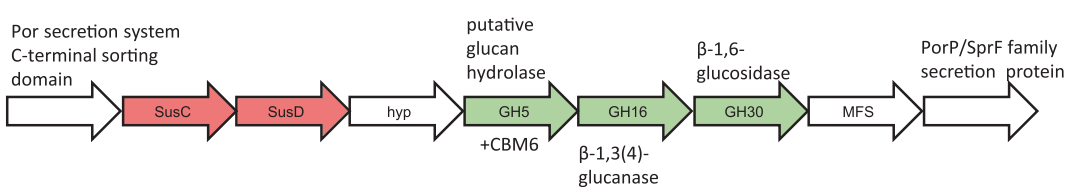

d PUL 148 of Gillisia sp. Hel1_86, PUL 166 of Gramella sp. MAR_2010_102

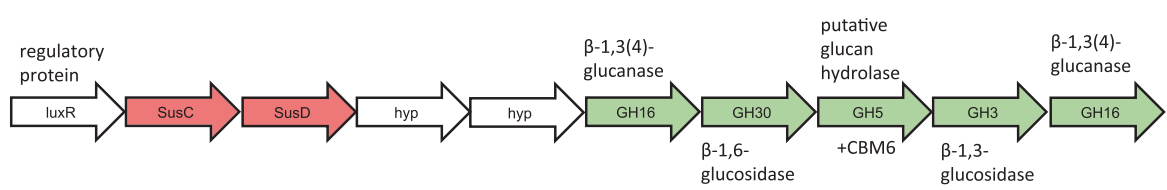

Fig. 2 Conserved PULs known (a, b) and predicted (c, d) to target laminarin

GH30 exo- $\beta$-1,6-glucanase removes $\beta$-1,6-glucose side chains from laminarin [45]. Although GH16 enzymes can hydrolyze both $\beta-1,3-$ and $\beta$-1,4-linked glucans, GH17 glucan hydrolases are highly specific to undecorated $\beta-1,3$ glucans and can have endo- [46] and exo-activity [47]. The $\beta$-1,3-glucan endohydrolase thus likely cleaves laminarin into oligosaccharides, which may be further degraded into glucose by the $\beta$-1,3-glucan exohydrolase.

Variants C and D PULs are likewise predicted to be capable of laminarin degradation based on gene content but have not been described before (Fig. 2c and d). They feature an additional putative GH5 glucan hydrolase with a carbohydrate-binding domain that binds $\beta-1,3-$ and $\beta-1,4-$ glucans (CBM6c, [48]). They furthermore contain GH16 and GH30 family enzymes as described in variant B, but no GH17 enzymes.

In total, 62\% (33/53) of all isolates and 78\% (25/32) of surface water isolates contained at least one laminarin PUL. Variant A occurred 21 times, B 17 times, C five times, and D two times (Supplementary Table S3). Eight isolates possessed two laminarin PULs (Flavobacteriaceae bacterium spp. MAR_2010_105 and MAR_2010_119, Gramella sp. MAR_2010_102, Polaribacter spp. Hel1_33_49, 78, 96 and Hel1_88 and Psychroserpens sp. Hel1_66) and three isolates contained three (Formosa spp. Hel3_A1_48 and Hel1_33_131, Flavobacteriaceae bacterium sp. Hel1_10). In contrast, laminarin PULs were far less prevalent in isolates obtained from the $>20 \mu \mathrm{m}$ retentate $(2 / 12)$. Laminarins are composed of a $\beta-1,3$-glucan backbone ramified by $\beta-1,6$ and, less frequently, $\beta-1,2$-linked glucose side chains [49]. The backbone length and ramification degree varies in different species. Laminarin of brown algae is capped at the reducing end by a 1-linked D-mannitol [50]. Only three isolates with laminarin PULs, namely the Polaribacter spp. Hel1_85 and KT25b and Gramella sp. MAR_2010_102, also possessed an annotated mannitol-2-dehydrogenase. It is possible that this enables utilization of brown algal laminarin. However, free mannitol is a more likely substrate. Growth on free mannitol has for example been demonstrated in the marine flavobacterium $Z$. galactanivorans [51]. Studies on Ectocarpus siliculosus have shown that brown algae can store substantial amounts of free mannitol as compatible osmolyte [52]. Furthermore it has recently been shown that free mannitol is likewise frequently found in various planktonic microalgae [53]. Interestingly, diatoms seem to have lost their ability to synthesize mannitol, although exceptions exist [53]. The fact that phytoplankton blooms in the southern North Sea are usually diatom- 
a $\alpha-1,4-$ glucan

PULs 318, 326 of Polaribacter spp. Hel1_88 and KT25b

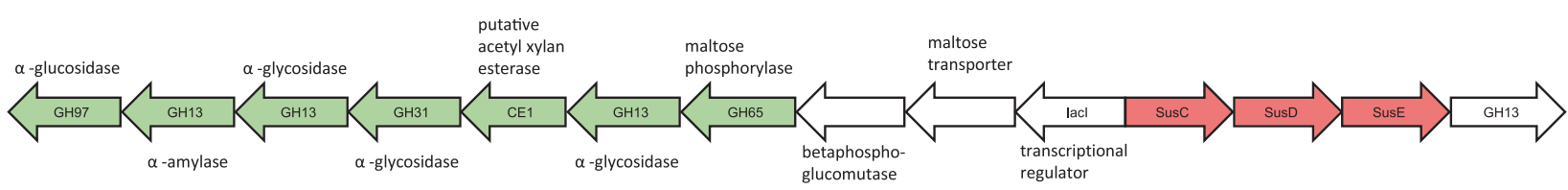

b alginate

PULs 102, 115 of Flavobacteriaceae bacterium spp. MAR_2010_105 and MAR_2010_119

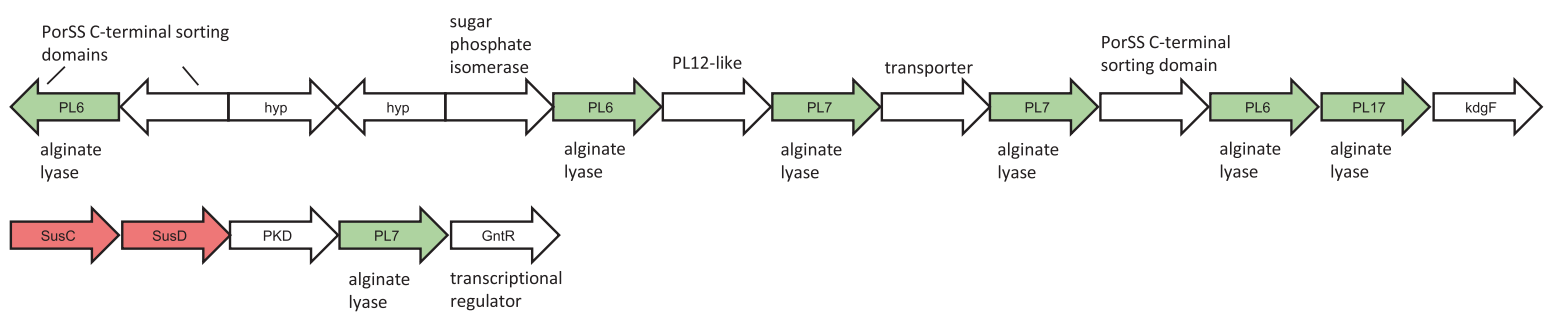

Fig. 3 PULs predicted to target $\mathbf{a} \alpha-1,4$-glucans and $\mathbf{b}$ alginate

dominated would hence explain, why mannitol-2dehydrogenase genes were rarely found in our isolates. Consequently, the majority of isolates with laminarin PULs seem to only target diatom-type non-mannitol-capped chrysolaminarins, indicating that these are the major available laminarins in the southern North Sea.

\section{a-1,4-glucan (starch, glycogen)}

PULs predicted to target $\alpha$-1,4-glucans, such as starch, glycogen, and amylose were also highly abundant (43/400 PULs, 37/53 isolates; Supplementary Table S3). Respective PULs often featured a susCDE-like gene triplet, at least one predicted GH13 $\alpha$-glycosidase and frequently GH65 phosphorylases as well as GH31 hydrolases acting on $\alpha$ glucosidic linkages (Fig. 3a). In some cases, these PULs also encoded a GH97 family glycoside hydrolase, known to hydrolyze diverse $\alpha-1,2-, \alpha-1,3-, \alpha-1,4-$, and $\alpha-1,6-$ linked glycosidic bonds [54, 55]. A similar PUL was first described for Gramella forsetii KT0803 and found to be upregulated in response to glucose-polymer substrates [13]. The PUL depicted in Fig. 3a likely facilitates utilization of $\alpha$ 1,4-glucans featuring $\alpha$-1,6-branches, such as the starch molecule amylopectin or potentially bacterial glycogen. Contrastingly, some isolates featured reduced versions of this PUL without any annotated susE- or susF-like gene and only one GH13 and GH65 gene, respectively (e.g., all Maribacter isolates). These isolates may only target simple non-branched $\alpha$-1,4-glucans such as maltodextrin or amylose. Recent investigations have shown that $B$. thetaiotaomicron SusE is an immobile outer membrane protein that can modify the preferred sizes of maltooligosaccharides for uptake [56, 57]. Hence SusE homologs, whereas not essential, might be generally involved in fine-tuning the size selection of glycan uptake.

\section{Alginate}

Twenty isolates featured in total 27 alginate-specific PULs (Fig. 1). Alginate consists of blocks of $\beta$-D-mannuronic acid and $\alpha$-L-guluronic acid, forming a linear $\beta$-1,4-linked chain [58]. Corresponding PULs encode family PL6, 7, and 17 alginate lyases (Fig. 3b). Six of the alginate PULs also contained genes with sequence similarities to the sparsely investigated PL12 family. Known PL12 enzymes cleave heparin-a polymer of $\beta$-1,4-linked uronic acids and glucosamine that is often highly sulfated [59]. Heparin and alginate hence are both linear, $\beta$-1,4-linked C5-uronans. However, sulfated alginates analogous to heparin, whereas being artificially synthesized for biotechnological uses [6062], have not been reported in nature. The latter is in line with a lack of sulfatases in the alginate PULs. Therefore, the PL12 family enzymes encoded in the alginate PULs likely represent novel types of alginate lyases. No PL15 and only one potential PL14 family alginate lyase (Lutibacter sp. Hel1_33_5, not PUL-associated) were annotated. The putative microalgae-associated cluster had a higher prevalence $(8 / 12)$ of alginate PULs as compared with the other isolates (12/41) (Fig. 1).

\section{Mannose-rich substrates}

Seventeen isolates harbor PULs rich in mannose-targeting CAZyme genes, e.g., from families GH26, 38, 76, 92, 125, 
a sulfated $\alpha$-glucuronomannan

PULs 289, 296, 300 of Polaribacter spp. Hel1_33_49, Hel1_33_78, and Hel1_33_96
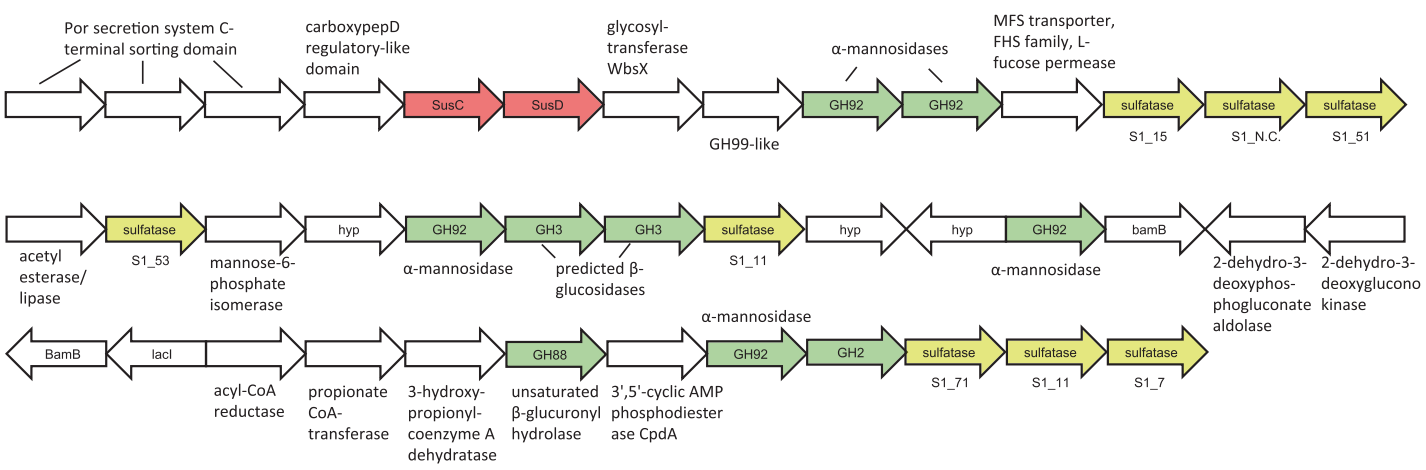

b a-mannan

PUL 340 of Salegentibacter sp. Hel1_6
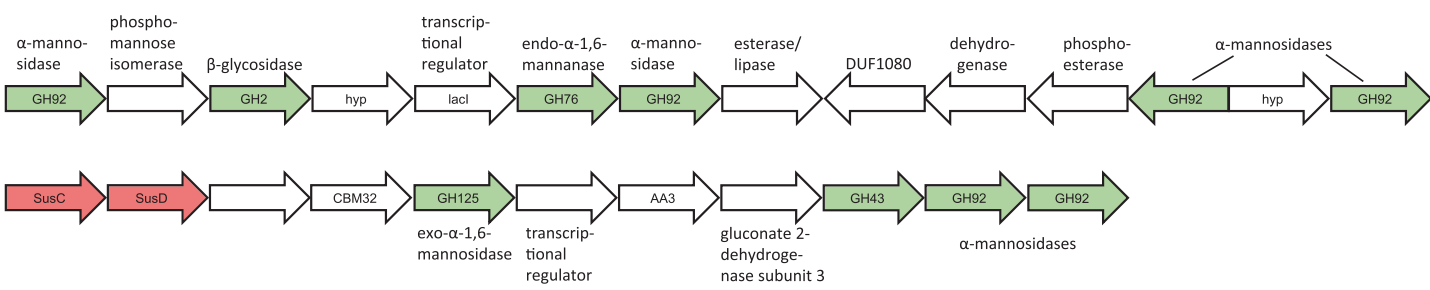

c $\beta$-mannan

PUL 196 of Leeuwenhoekiella sp. MAR_2009_132

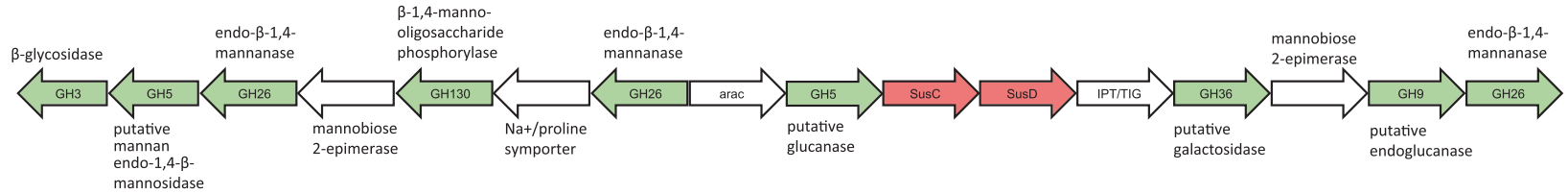

Fig. 4 Selected PULs predicted to target mannose-rich substrates. Possible targets are a a sulfated $\alpha$-mannan, $\mathbf{b}$ a non-sulfated $\alpha$-mannan, and $\mathbf{c}$ a non-sulfated $\beta$-mannan. For sulfatases, families and sub-families are indicated below the genes

and 130 (Fig. 1, Supplementary Table S5). These PULs share little conservation in terms of gene arrangements, and only few contain a GH76 endo- $\alpha-1,6$-mannanase (2/17) or a GH26 family endo- $\beta-1,4-$ mannanase (5/17), indicative for either a linear $\alpha-1,6$ - or $\beta-1,4-$ mannan backbone. Instead, GH92 and GH130 family genes are particularly prevalent. The GH92 family comprises solely exo-acting $\alpha$-mannase genes. PULs rich in GH92 genes thus might target $\alpha$ mannose-rich $\mathrm{N}$-glycosylated glycoproteins that occur widespread in eukaryotes, including algae. GH130 enzymes comprise phosphorylases and glycoside hydrolases that act on $\beta$-mannosides and are known to partake in the degradation of $\beta$-mannans [63].

The alpha-mannosidase-encoding PULs can be divided into two subtypes: (A) PULs containing multiple GH92 ( $\alpha$ $1,2 / 3 / 4 / 6)$ genes that are often also rich in sulfatase genes (Fig. 4a; e.g., Supplementary Table S3: PULs 289, 296, 300 of Polaribacter spp. Hel1_33_49/78/96; PUL126 of Formosa sp. Hel1_33_131), and (B) PULs with $\alpha$-mannan- targeting CAZymes of diverse additional families, such as GH76 endo- $\alpha-1,6$-mannanases, GH125 exo- $\alpha$-1,6-mannosidases or GH38 $\alpha$-mannosidases $(\alpha-1,2 / 3 / 6)$. These type (B) PULs are notably devoid of sulfatase-coding genes, indicating a non-sulfated substrate (Fig. 4b). A PUL with a similar CAZyme repertoire in B. thetaiotaomicron facilitates utilization of yeast cell wall $\alpha$-mannan [64]. Type (A) sulfatase- and GH92-rich PULs have been observed previously in Polaribacter-affiliated North Atlantic fosmids [65] and Polaribacter sp. Hel1_33_49 [14] and therefore seem to be widespread. In our case the PUL contains additional GH2, 3 and 88 family enzymes (Fig. 4a). Whereas GH families 2 and 3 are functionally diverse, GH88 enzymes are unsaturated $\beta$-glucuronyl hydrolases. This functional combination of CAZymes suggests degradation of $\alpha$-glucomannans such as glucuronomannan, a polysaccharide that has been reported for diatoms [17, 19, 49] and brown algae [66] and thus should be abundant in the southern North Sea. Finally, co-located peptidases and a 
a fucose-containing sulfated polysaccharide

PUL 231 of Maribacter forsetii sp. DSM_18668

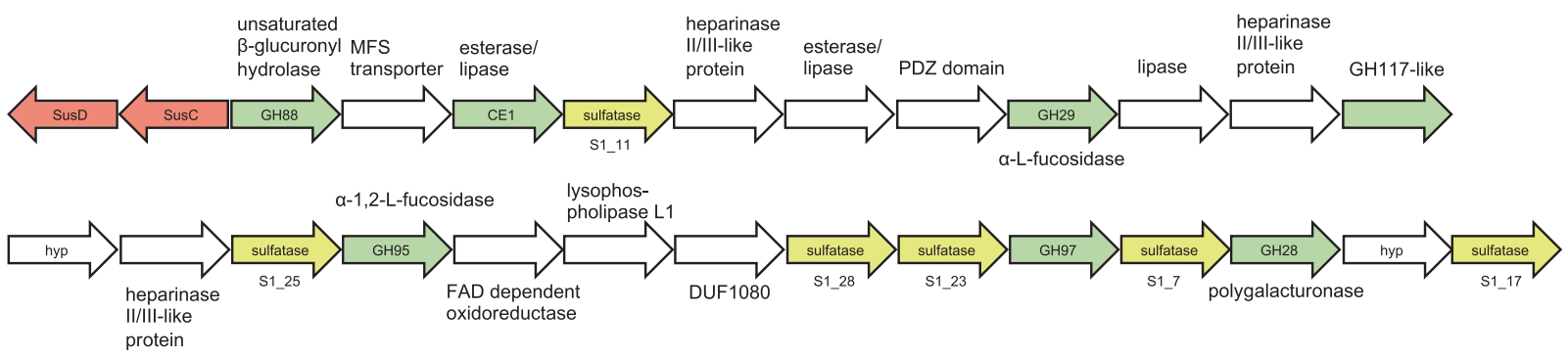

b $\beta$-xylose-containing sulfated polysaccharide

PUL 136 of Formosa sp. Hel3_A1_48

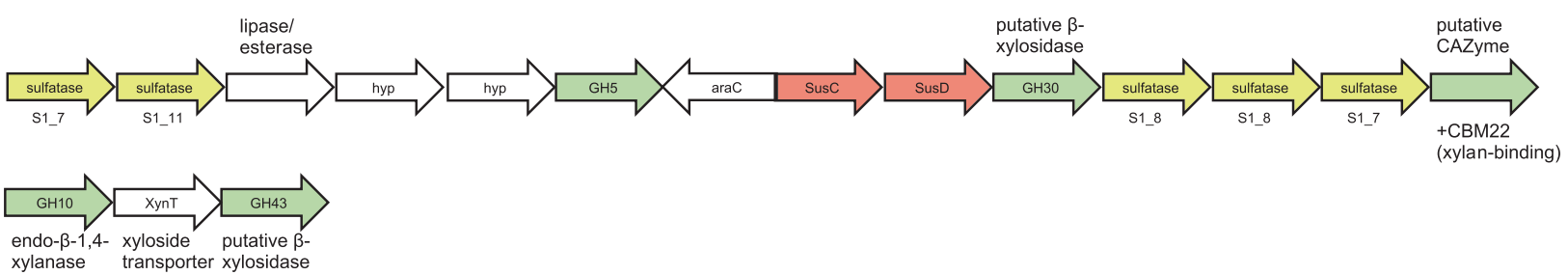

Fig. 5 PULs predicted to target sulfated substrates rich in a fucose (FCSP) and b xylose. For sulfatases, families, and sub-families are indicated below the genes

gene distantly related to GH99, a family that is reported to contain glycoprotein endo- $\alpha$-mannosidases, indicate that this hypothesized glucuronomannan substrate might be a glycoprotein. However, functional studies are required to support this hypothesis. Le Costaouëc and colleagues [19] recently revealed the main cell wall polysaccharide of the diatom Phaeodactylum tricornutum and possibly many other diatoms [67] to be a 'linear poly- $\alpha-1-3-$ mannan decorated with sulfate ester groups and $\beta$-D-glucuronic residues'.

The $\beta$-mannan PULs (Fig. 4c) all contained GH130 $\beta-1,2$ (4)-mannooligosaccharide phosphorylases and GH26 CAZymes which are primarily composed of predicted endo$\beta-1,4-$ mannanases (Supplementary Table S3: PUL 6 of Flavobacteriaceae bacterium sp. Hel1_10; PUL 196 of Leeuwenhoekiella sp. MAR_2009_132; PUL 211 of Flavimarina sp. Hel1_48; PUL266 of Muricauda sp. MAR_2010_75; PUL 342 of Salegentibacter sp. Hel1_6). Beta-mannans have been reported in the red macroalga Porphyra umbilicalis and in various species of the green macroalga Codium. Moreira and Filho [68] proposed that 'in some algae species, linear (beta-) mannan seems to replace cellulose as the main cell wall glycan'.

\section{Fucose-containing sulfated polysaccharides (FCSP)}

Twenty PULs in 14 isolates suggest that FCSPs are also common substrates to marine Flavobacteriia. A prominent substrate of this group is fucoidan, a highly diverse polysaccharide prominent in brown algae. It contains L-fucose and sulfate ester groups owing to its backbone of $\alpha-1,3$ or alternating $\alpha-1,3 / 1,4$-linked L-fucopyranosyl residues [69]. This backbone has side chains containing diverse other monosaccharides, uronic acids, acetyl groups, and proteins [70]. In accordance with the structural complexity of FCSPs, PULs display equally complex gene repertoires, averaging 38 genes per PUL. A relatively short PUL is exemplarily shown in Fig. 5a. Characteristic CAZymes of predicted FCSP PULs in the isolated Flavobacteriia were GH29 and GH95 family $\alpha$-L-fucosidases or potentially $\alpha$-Lgalactosidases. Other regularly co-occurring CAZymes included GH117 family enzymes (Supplementary Table S5), $\beta$-xylosidases mostly of the family GH43, but also GH30, 39, and 120 , and diverse $\alpha$ - and $\beta$-glucosidases of the families GH2, 3, 31, and 97. Sulfated FCSPs such as xylofucoglucans or -glucuronans have been reported for brown algal hemicelluloses [3,9] and might also occur in diatoms [49].

\section{$\beta$-xylose-containing substrates}

Twenty-two PULs predicted to target $\beta$-xylose-rich substrates were found in 14 isolates (Fig. 1, Supplementary Table S3). Likely substrates are heterogeneous $\beta$-xylans such as arabinoxylans, glucuronoxylans, and sulfated xyloglucans. These PULs encode GH10 and GH43 
enzymes targeting xylans, as well as GH30, 115, and 67 enzymes. GH10 enzymes are endo- $\beta-1,4$-xylanases capable of cleaving large $\beta-1,4$-xylan backbones into oligosaccharides. GH30 and GH43 enzymes have broader degradation capacities, and while both families contain $\beta$-xylosidases, they were also reported to target mixed xylose-containing substrates such as arabinoxylan and $\alpha$-L-arabinofuranosides (GH43) or even completely different substrates such as $\beta$ glucosylceramidase or $\beta$-1,6-glucanase (GH30). GH67 and 115 can cleave glucuronic acid side chains from native xylans and are present in four PULs that might target glucuronoxylans (PULs 243, 256 of Maribacter spp. Hel1_7, MAR_2009_72; PUL 269 of Muricauda sp. MAR_2010_75; PUL 338 of Salegentibacter sp. Hel1_6; Supplementary Table S3). Two PULs were predicted to target arabinoxylans through a GH51 $\alpha$-L-arabinofuranosidase (PUL 155 of Gramella forsetii KT0803; PUL 199 of Flavimarina sp. Hel1_48; Supplementary Table S3). Four PULs predicted to target $\beta$-xylose-rich substrates encode sulfatases (PUL136 of Formosa sp. Hel3_A1_48, Fig. 5b; PULs 363, 364, 366 of Zobellia amurskyensis MAR_2009_138; Supplementary Table S3). Marine xylans have been reported as hemicellulose components in green [71], red and brown macroalgae [3, 72], and as cell wall components in some diatoms $[73,74]$.

\section{Further substrates}

Further possible substrates comprised sulfated $\alpha$-rhamnoseand $\alpha$-galactose-containing substrates, pectin, arabinan, trehalose-like $\alpha$-1,1-glucans, $N$-acetylglucosamine and its polymer chitin, digeneaside, fructose, and sialic acidcontaining polysaccharides. These compounds are discussed in the supplementary text.

\section{Trees of SusC- and SusD-like proteins reveal substrate-specific clusters}

We computed trees for all SusC- and SusD-like protein sequences of the 400 isolate PULs and obtained pronounced clusters for many of the predicted polysaccharide substrates (Fig. 6). For clarity, functionally heterogeneous or undefined clusters are depicted as gray triangles (complete trees: Supplementary files 1,2). Well-defined clusters in both trees included the structurally simple polysaccharides laminarin, $\alpha-1,4$-glucans and alginate. For example, SusDlike proteins of laminarin-targeting PULs of Cellulophaga sp. RHA_52, Flavobacteriaceae bacterium sp. Hel1_10, Formosa sp. Hel1_33_131 and Psychroserpens sp. Hel1_66 (PULs 58, 71, 128, 331, Supplementary Table S3), exhibited between 64 and $78 \%$ identity (Supplementary Table S4), whereas identity to SusD-like sequences from other PULs within the same respective genome was only $10-25 \%$ (data not shown).

SusC/D-like proteins from conserved PULs for these structurally simple substrates were more closely related than those from more variable PULs targeting structurally more diverse substrate classes such as FCSPs or xylose-rich substrates (Supplementary Table S4). This is visible in the trees by shorter and longer respective branch lengths (Fig. 6). Some substrates formed multiple clusters, for example xylose-rich substrates. This might indicate either rather different xylose-containing substrates or multiple ways of attack and uptake for a given class of xylosecontaining substrate.

The topologies of the SusC- and SusD-like protein trees were notably congruent regarding branching patterns of the identified substrate-specific clusters. Only the pectin cluster was located at a distinctly different position. SusC- and SusD-like proteins from the same PULs exhibited a strong tendency to occur in corresponding substrate-specific clusters in both trees. This applied to $>70 \%$ of the SusC and SusD sequences within identified substrate-specific clusters (Supplementary Figures S1A and B).

\section{SusC/D-like protein expression of bacterioplankton during phytoplankton blooms supports temporal variations of polysaccharide abundances in situ}

SusC/D-like proteins range among the highest expressed proteins in bacterioplankton metaproteomes from productive oceans $[36,75,76]$. Likewise, studies on flavobacterial isolates have identified SusC/D-like proteins as the highest expressed proteins within PULs that are furthermore coregulated with other PUL-encoded proteins including CAZymes [13, 14]. SusC/D expression thus represents a suitable proxy for overall PUL expression

We monitored bacterioplankton spring phytoplankton blooms in the southern North Sea during 2009 with weekly, and in 2010 to 2012 with about monthly sampling [32, 36]. At 14 selected time points we analyzed the free-living 0.2-3 $\mu \mathrm{m}$ bacterioplankton using shotgun metaproteomics (total: 23,917 identified proteins), and detected high numbers of expressed SusC/D-like proteins in metaproteomes across all sampled years (Supplementary Table S2).

To identify potential substrates, we aligned all expressed SusC/D-like sequences (SusC: 390; SusD: 118) to the SusC/ D-tree constructed from isolate PULs. Isolate sequences with highest similarities $(\geq 40 \%)$ to expressed sequences are indicated in Fig. 6. Further semi-quantitative analyses were confined to SusC/D-like proteins where at least one related homolog reached expression levels of $\geq 0.05 \%$ NSAF, i.e. $0.05 \%$ of all mass-adjusted spectral counts (see Materials and methods; Fig. 7). 
Fig. 6 Trees of all PULassociated SusC- (a) and SusDlike (b) proteins of the Flavobacteriia isolates showing functional, substrate-specific clustering. Protein sequences were aligned using the MAFFT G-INS-i algorithm and trees were calculated using FastTree 2.1.5 approximate-maximum likelihood (SusC-like: 370; SusD-like: 362). Substrate predictions are depicted in colors. Proteins with expressed homologs in North Sea bacterioplankton blooms of more than $40 \%$ sequence identity are marked with asterisks (and number of homologs if $x>1$ ).

Corresponding figures labeled with protein sequence identifiers, originating species and PUL-associated CAZymes are provided as supplementary material a

Tree scale:

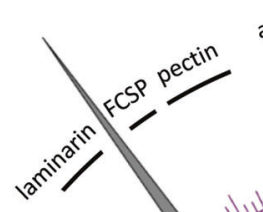

alginate rhamnan

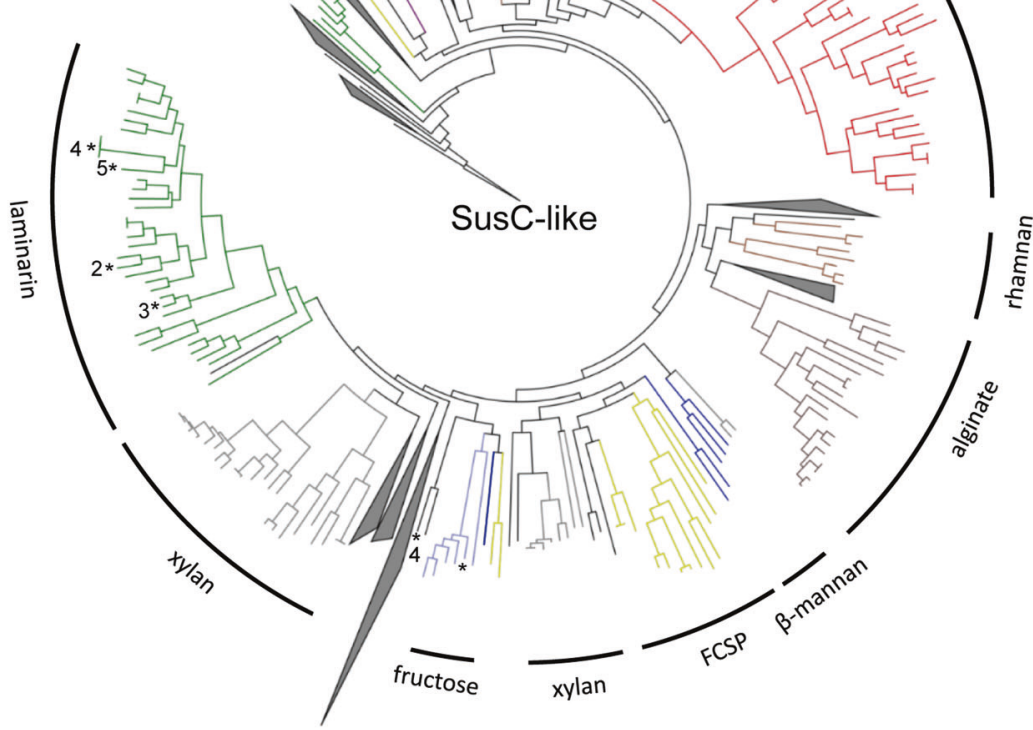

b

Tree scale: 1
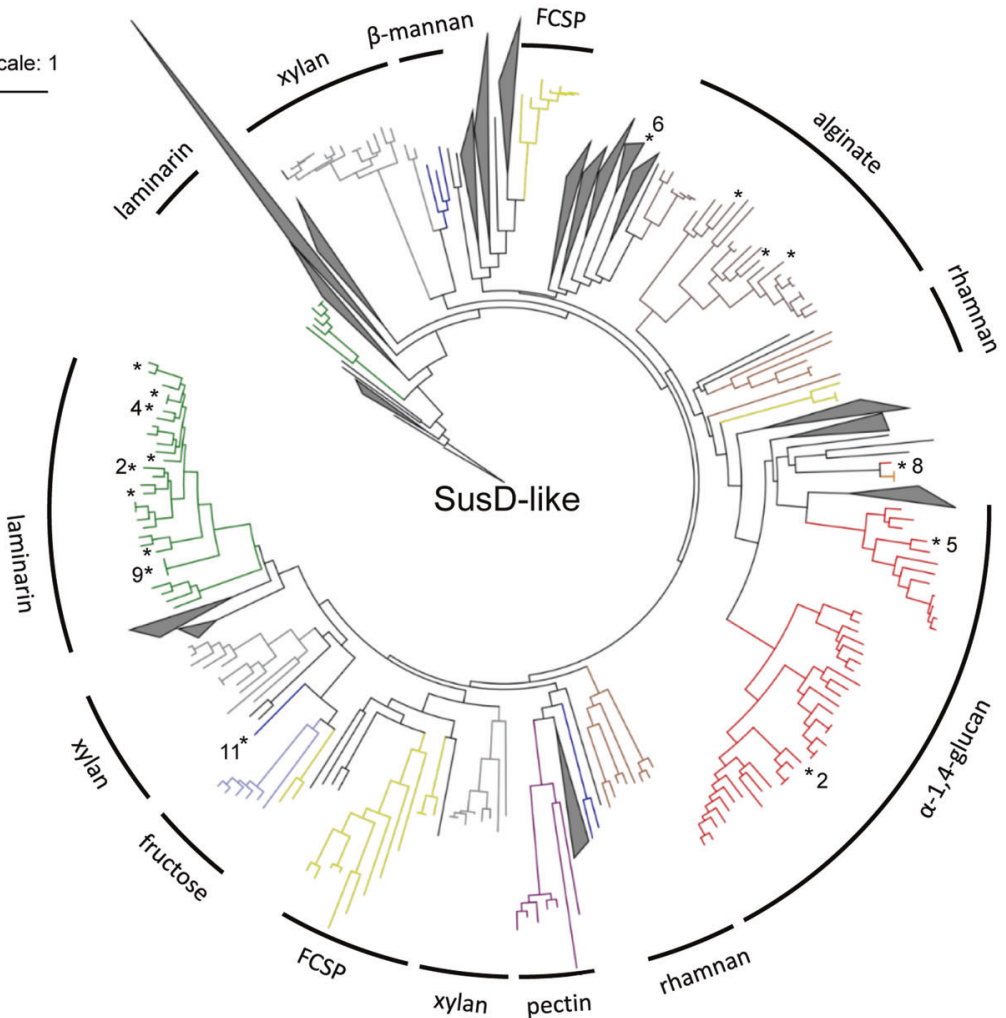
a

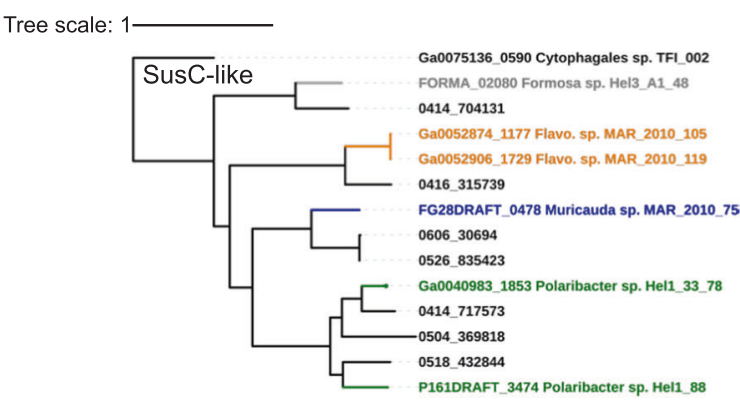

b

Tree scale: $1-$

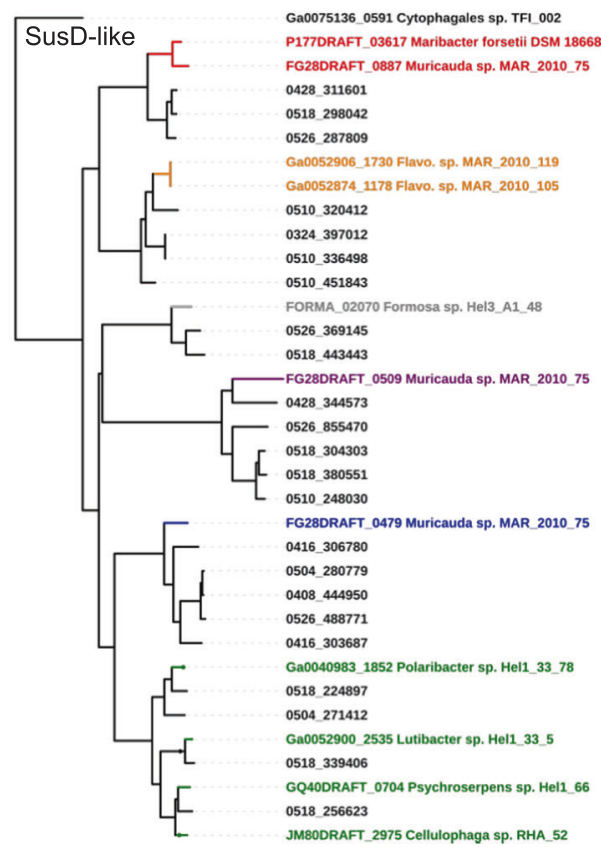

c

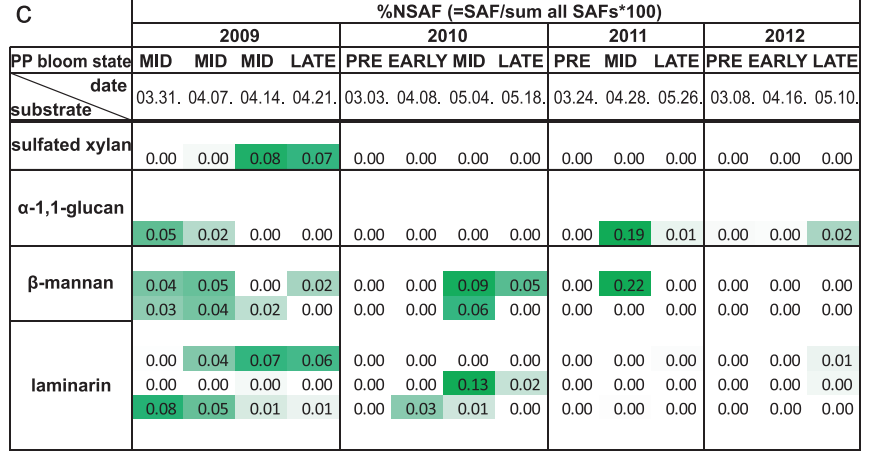

d

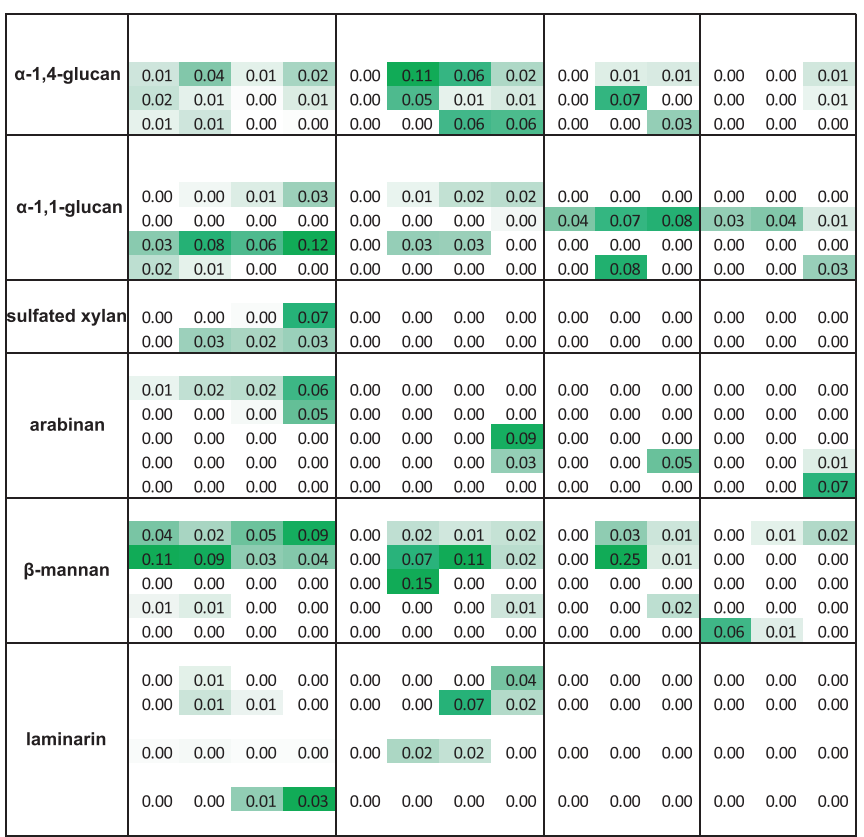

Fig. 7 a, b Trees of expressed SusC and SusD-like proteins identified in 3-0.2 $\mu$ m bacterioplankton during North Sea spring phytoplankton blooms in 2009-2012 using proteomics. The most closely related SusC/D-like sequences from North Sea Flavobacteriia isolates in this study were integrated in the tree. Protein names correspond to sequence identifier and isolate name. Sequences were aligned using the MAFFT G-INS-i algorithm. The tree was calculated using FastTree 2.1.5 approximate-maximum likelihood. c, d Corresponding expression levels as Normalized Spectral Abundance Factors (\%NSAF) for the four consecutive blooms. Metaproteomic samples were classified as pre-, early-, mid-, and latebloom based on chlorophyll $a$ concentrations during the spring phytoplankton blooms. Expression levels are highlighted by green color

\section{Laminarin}

Homologs to laminarin-binding SusC-like proteins were detected amidst the 2009 and 2010 phytoplankton blooms, with one homolog reaching a notable maximum of $0.13 \%$ NSAF on May 4th, 2010 (Fig. 7b). Respective SusD-like homologs were detected in the same years and highest expression was observed at the same date in 2010 (0.07\% \%SAF, Fig. 7d). Amino-acid identities of expressed SusC homologs and laminarin PUL SusC-like proteins from isolates ranged from 48-68\%, and for SusD homologs from 40-78\% (Supplementary Table S4). Our data suggest that laminarin occurred at the bloom peaks in 2009 and 2010 and directly thereafter. This is supported by detection of expressed GH3 $\beta$-glucosidases and GH16 $\beta$-glucanases in 2009 [36] and, to a lesser degree, in 2010 (Supplementary Table S2). Chrysolaminarin is produced by microalgae such as Thalassiosira nordenskioeldii diatoms or representatives of Phaecystis haptophytes [77, 78], which both were among the dominating microalgae in 2009 and 2010 [32].

\section{Alpha-1,4-glucan}

Respective SusD-like proteins were most abundantly detected in 2010, peaking on April 8th $(0.11 \%$ NSAF, Fig. 7d), but also in 2009 and 2011. Sequence identities to 
isolate $\alpha$-1,4-glucan PUL SusD-like proteins ranged from 43 to $46 \%$ (Supplementary Table S4). These data indicate that $\alpha-1,4$-glucans, potentially starch or glycogen, represented a recurring substrate from 2009 to 2011 during early to late phytoplankton bloom stages.

\section{Alpha-1,1-glucan}

An $\alpha$-1,1-glucan-binding SusC-like protein potentially targeting a trehalose-like substrate was strongly expressed on April 28th 2011 (0.19 \%NSAF; Fig. 7b), but also in all other years except 2010. Its sequence identity to the SusClike proteins of the trehalose PULs of Flavobacteriaceae bacterium spp. MAR_2010_105 and MAR_2010_119 was 43\% (Supplementary Figure S2J, PUL103 and PUL116, Supplementary Tables S3 and S4). Corresponding SusDlike proteins were detected in all years, but most strongly throughout the blooms of 2009 and 2011. Their protein identities to the isolate PULs ranged from 58-59\% (Supplementary Table S4).

\section{Sulfated $\beta$-xylan}

One SusC and two SusD-like proteins likely targeting a sulfated $\beta$-xylan were expressed in the mid and late stages of the phytoplankton bloom of 2009, peaking at $0.08 \%$ NSAF for SusC-like proteins and $0.07 \%$ NSAF for SusDlike proteins. Their identities to homologs of the sulfated $\beta$ xylan PUL of Formosa sp. Hel3_A1_48 (Fig. 5b, PUL136, Supplementary Table S3) was 53\% and 49-53\%, respectively (Supplementary Table S4).

\section{Beta-mannan}

Homologs with high identities to SusC/D-like proteins occurring in a predicted $\beta$-mannan PUL from Muricauda sp. MAR_2010_75 were strongly expressed during blooms from 2009 to 2011, peaking on April 28th 2011 for SusC (0.22 \%NSAF) and SusD (0.25 \%NSAF) homologs. No SusC-like proteins of putative $\beta$-mannan PULs were detected in 2012 and SusD-like expression was likewise much weaker. The expressed SusC-like proteins were $52-60 \%$ identical to the ones from the $\beta$-mannan PUL of Muricauda sp. MAR_2010_75 (PUL266, Supplementary Table S3) and the SusD-like proteins showed 45-51\% identity (Supplementary Table S4). The predicted $\beta$-mannan PUL of Muricauda sp. MAR_2010_75 harbors two pairs of SusC/D-like proteins. The one with expressed in situ homologs did not cluster with those from other betamannan PULs in our SusC/D trees. Hence the two SusC/Dlike pairs might target different oligosaccharides. As some PULs can be induced by substrates other than those that they degrade, it is possible that the substrate that led to the upregulation of the in situ homologs was not a betamannan. Proteomic studies of this PUL in Muricauda sp. MAR_2010_75 are required to clarify regulation of this PUL and to interpret the in situ data.

\section{Arabinan}

SusD-like proteins potentially targeting an arabinan were expressed at late phytoplankton blooms stages during all four years with at least $0.05 \% \mathrm{NSAF}$. However, their identities to the SusD-like protein of a predicted arabinan PUL from Muricauda sp. MAR_2010_75 were only 26-30\% (Supplementary Figure S2I, PUL267, Supplementary Tables S3 and S4).

In summary, comparative analyses of SusC/D homolog expression are indicative of a successive utilization of different polysaccharides over the course of phytoplankton blooms. This agrees with successive changes in the microbial community composition during bloom events that we reported earlier on $[32,36]$.

\section{Discussion}

PUL function predictions in this study are based on sequence similarity analyses and thus cannot rival timeconsuming laboratory-based functional studies in terms of accuracy. Knowledge on polysaccharides from marine algae, in particular from microalgae, is still sparse and thus false predictions are possible. Still, the holistic approach to analyze the PUL spectrum of a large number of isolates from a single habitat allows identification of recurrent and thus important PULs as targets for future functional studies and to build testable hypotheses on possible substrates.

We observed diverse polysaccharide degradation capacities among North Sea Flavobacteriia with no distinct correlation to taxonomy. Even isolates from identical genera often featured notably diverging PUL repertoires and genome sizes (e.g., Polaribacter, Maribacter, and Cellulophaga), substantiating earlier data [14]. Our findings suggest that a species' PUL repertoire is more dependent on its distinct ecological niche, whereas its phylogeny is of secondary importance. This corroborates the hypothesis that PULs are exchanged between Flavobacteriia through horizontal gene transfer [10].

The isolates' PUL repertoires showcase that abundant, structurally simple substrates such as laminarin, $\alpha-1,4$-glucans, and alginate are targeted by likewise conserved and frequent PULs. These substrates are likely so common that preserving the respective catabolic machinery is favorable for many marine Flavobacteriia. Diatom-derived chrysolaminarin has been estimated to amount to 5-15 petagrams of organic carbon annually [78] and accordingly laminarin- 
specific PULs were frequent in our surface water isolates. The four predicted laminarin PUL variants we identified might indicate that different laminarin types [49] are targeted by different PULs or that some of these PULs act as helper modules in laminarin degradation, as many species feature more than one laminarin PUL type (e.g., Formosa spp. Hel1_33_131 and Hel3_A1_48, Gramella sp. MAR_2010_102). Variant B contains predicted endo- and exo-acting $\beta$-1,3-glucan hydrolases (GH17) highly specific to laminarin degradation [45]. Variants A, C, and D only contain GH16 endo-1,3(4)- $\beta$-glucanases and may not be restricted to laminarin, but are potentially capable of degrading further mixed-linkage $\beta-1,3 / 1,4$-glucans, as recently shown for a similar conserved PUL in human gut Bacteroidetes [44]. Clustering of the SusC/D sequences of variants $A, B$ and $D$ in the $S u s C / D$ trees support that they bind the same substrate (Supplementary Figure S1A, B). Those of variant $\mathrm{C}$, however, are located elsewhere, indicating that this PUL might indeed have an alternate function. Functional studies on model strains containing variant C (e.g., Formosa sp. Hel3_A1_48) and D (e.g., Gramella sp. MAR_2010_102) will be necessary to ultimately elucidate the functions of these PULs.

Alginate and $\alpha$-1,4-glucan degradation capacities were prevalent in the isolates obtained from the $>20 \mu \mathrm{m}$ retentate, which might be microalgae-associated, but were also common in many seawater isolates. Overall, laminarin, $\alpha$ 1,4-glucan, and alginate PULs are fairly conserved and make up over a quarter of all PULs in the isolates (115/ 400), suggesting that these are abundant polysaccharide substrates in North Sea coastal habitats that many microbes can consume and likely compete for.

Other substrates are utilized by fewer isolates, which implies that algal polysaccharide degradation is usually carried out by multiple resource-partitioning bacterioplankton species. In putative microalgae-associated isolates, these substrates include new FCSP variants, and xylose- and rhamnose-rich polysaccharides. Among surface water isolates, these substrates are sulfated $\alpha$-mannans (likely an $\alpha$-glucuronomannan glycoprotein), $\beta$-mannans, sulfated $\alpha$-galactans and $\beta$-xylans, chitin, and (trehalose-like) $\alpha$-1,1-glucans.

A major result of this study is the substrate-specific clustering of both SusC- and SusD-like proteins. The strong tendencies of SusC and SusD homologs to occur in corresponding substrate-specific clusters in both trees, resulting in similar tree topologies, suggest coevolution of these two proteins. This hypothesis is corroborated by recent X-ray crystallography findings showing complex formation of two SusC- and SusD-like proteins of B. thetaiotaomicron [7]. Clustering was more pronounced for structurally conserved, simple polysaccharides than for the heterogeneous and partially new substrates described in this study. This is expected, as heterogeneous substrates are attacked at multiple points resulting in a variety of structurally different oligosaccharides for uptake. Furthermore, broad substrate classes that currently can only be defined as, e.g., FCSPs or xylose-containing substrates might actually represent multiple chemically rather different substrates. Hence, improvement of functional clustering is to be expected once more detailed knowledge on algal polysaccharides structures is available.

We here provide first metaproteomic data indicating that high-resolution expression analysis of SusC/D homologs may be used for monitoring changes in microbial polysaccharide degradation activity. This provides a proxy on which polysaccharides are important at a given time and space in marine carbon cycling. Considering our still incomplete knowledge, only expressed SusC/D homologs exhibiting a high level of sequence identity to functionally annotated or characterized SusC/D sequences should be considered. Absence of such expressed homologs, however, does not preclude that a respective substrate may be targeted by an as yet unknown SusC/D system. This current limitation notwithstanding, our approach provides a new method to identify environmentally relevant polysaccharide substrates that due to their structural complexity are still difficult to identify by direct chemical analysis.

Acknowledgements We thank Sabine Kühn and Ingrid Kunze for cultivation and DNA extraction and Bernhard Fuchs for critical reading. Genome sequencing and assembly was conducted in the framework of the COGITO project by the US Department of Energy Joint Genome Institute, a DOE Office of Science User Facility, and is supported by the Office of Science of the US Department of Energy under Contract No. DE-AC02-05CH11231. This study was funded by the Max Planck Society and supported by the Deutsche Forschungsgemeinschaft (DFG) in the framework of the research unit FOR2406 'Proteogenomics of Marine Polysaccharide Utilization (POMPU)' by grants of Rudolf Amann (AM 73/9-1), Hanno Teeling (TE 813/2-1), and Thomas Schweder (SCHW 595/10-1) and the DFG Emmy Noether program (Jan-Hendrik Hehemann grant HE 7217/1-1). Lennart Kappelmann and Karen Krüger are members of the International Max Planck Research School of Marine Microbiology (MarMic).

\section{Compliance with ethical standards}

Conflict of interest The authors declare no conflict of interest.

Open Access This article is licensed under a Creative Commons Attribution 4.0 International License, which permits use, sharing, adaptation, distribution and reproduction in any medium or format, as long as you give appropriate credit to the original author(s) and the source, provide a link to the Creative Commons license, and indicate if changes were made. The images or other third party material in this article are included in the article's Creative Commons license, unless indicated otherwise in a credit line to the material. If material is not included in the article's Creative Commons license and your intended use is not permitted by statutory regulation or exceeds the permitted use, you will need to obtain permission directly from the copyright holder. To view a copy of this license, visit http://creativecommons. org/licenses/by/4.0/. 


\section{References}

1. Field CB, Behrenfeld MJ, Randerson JT, Falkowski P. Primary production of the biosphere: integrating terrestrial and oceanic components. Science. 1998;281:237-40.

2. Kraan S. Algal polysaccharides, novel applications and outlook. In: Chang C-F, editor. Carbohydrates-Comprehensive Studies on Glycobiology and Glycotechnology. InTech, London. (ISBN 978953-51-0864-1); 2012. https://www.intechopen.com/books/ca rbohydrates-comprehensive-studies-on-glycobiology and https:// www.glycotechnology/algal-polysaccharides-novel-applications-a nd-outlook.

3. Kloareg B, Quatrano RS. Structure of the cell walls of marine algae and ecophysiological functions of the matrix polysaccharides. Oceanogr Mar Biol Annu Rev. 1988;26:259-315.

4. Hoagland KD, Rosowski JR, Gretz MR, Roemer SC. Diatom extracellular polymeric substances: function, fine structure, chemistry, and physiology. J Phycol. 1993;29:537-66.

5. Laine RA. A calculation of all possible oligosaccharide isomers both branched and linear yields $1.05 \times 10(12)$ structures for a reducing hexasaccharide: the Isomer Barrier to development of single-method saccharide sequencing or synthesis systems. Glycobiology. 1994;4:759-67.

6. Bjursell MK, Martens EC, Gordon JI. Functional genomic and metabolic studies of the adaptations of a prominent adult human gut symbiont, Bacteroides thetaiotaomicron, to the suckling period. J Biol Chem. 2006;281:36269-79.

7. Glenwright AJ, Pothula KR, Bhamidimarri SP, Chorev DS, Baslé A, Firbank SJ, et al. Structural basis for nutrient acquisition by dominant members of the human gut microbiota. Nature. 2017;541:407-11.

8. Martens EC, Lowe EC, Chiang H, Pudlo NA, Wu M, McNulty $\mathrm{NP}$, et al. Recognition and degradation of plant cell wall polysaccharides by two human gut symbionts. PLoS Biol. 2011;9: e1001221.

9. Popper ZA, Michel G, Hervé C, Domozych DS, Willats WG, Tuohy MG, et al. Evolution and diversity of plant cell walls: from algae to flowering plants. Annu Rev Plant Biol. 2011;62:567-90.

10. Hehemann JH, Kelly AG, Pudlo NA, Martens EC, Boraston AB. Bacteria of the human gut microbiome catabolize red seaweed glycans with carbohydrate-active enzyme updates from extrinsic microbes. Proc Natl Acad Sci USA. 2012;109:19786-91.

11. Hehemann JH, Correc G, Barbeyron T, Helbert W, Czjzek M, Michel G. Transfer of carbohydrate-active enzymes from marine bacteria to Japanese gut microbiota. Nature. 2010;464:908-12.

12. Thomas F, Barbeyron T, Tonon T, Génicot S, Czjzek M, Michel G. Characterization of the first alginolytic operons in a marine bacterium: from their emergence in marine Flavobacteriia to their independent transfers to marine Proteobacteria and human gut Bacteroides. Environ Microbiol. 2012;14:2379-94.

13. Kabisch A, Otto A, König S, Becher D, Albrecht D, Schüler M, et al. Functional characterization of polysaccharide utilization loci in the marine Bacteroidetes 'Gramella forsetii' KT0803. ISME J. 2014;8:1492-502.

14. Xing P, Hahnke RL, Unfried F, Markert S, Huang S, Barbeyron T, et al. Niches of two polysaccharide-degrading Polaribacter isolates from the North Sea during a spring diatom bloom. ISME J. 2015;9:1410-22.

15. Ficko-Blean E, Préchoux A, Thomas F, Rochat T, Larocque R, $\mathrm{Zhu} \mathrm{Y}$, et al. Carrageenan catabolism is encoded by a complex regulon in marine heterotrophic bacteria. Nat Commun. 2017; $8: 1685$.

16. Barbeyron T, Thomas F, Barbe V, Teeling H, Schenowitz C, Dossat C, et al. Habitat and taxon as driving forces of carbohydrate catabolism in marine heterotrophic bacteria: example of the model algae-associated bacterium Zobellia galactanivorans Dsij. Environ Microbiol. 2016;18:4610-27.

17. Ford CW, Percival E. 1299. Carbohydrates of Phaeodactylum tricornutum. Part II. A sulphated glucuronomannan. J Chem Soc. 1965;0:7042-6.

18. Rees DA, Welsh EJ. Secondary and tertiary structure of polysaccharides in solutions and gels. Angew Chem Int Ed. $1977 ; 16: 214-24$

19. Le Costaouëc T, Unamunzagab C, Manteconb L WH. New structural insights into the cell-wall polysaccharide of the diatom Phaeodactylum tricornutum. Algal Res. 2017;26:172-9.

20. Hahnke RL, Harder J. Phylogenetic diversity of Flavobacteria isolated from the North Sea on solid media. Syst Appl Microbiol. 2013;36:497-504.

21. Hahnke RL, Bennke CM, Fuchs BM, Mann AJ, Rhiel E, Teeling $\mathrm{H}$, et al. Dilution cultivation of marine heterotrophic bacteria abundant after a spring phytoplankton bloom in the North Sea. Environ Microbiol. 2015;17:3515-26.

22. Bauer M, Kube M, Teeling H, Richter M, Lombardot T, Allers E, et al. Whole genome analysis of the marine Bacteroidetes 'Gramella forsetii' reveals adaptations to degradation of polymeric organic matter. Environ Microbiol. 2006;8:2201-13.

23. Reddy TB, Thomas AD, Stamatis D, Bertsch J, Isbandi M, Jansson J, et al. The genomes OnLine database (GOLD) v.5: a metadata management system based on a four level (meta)genome project classification. Nucleic Acids Res. 2015;43:D1099-106.

24. Aziz RK, Bartels D, Best AA, DeJongh M, Disz T, Edwards RA, et al. The RAST server: rapid annotations using subsystems technology. BMC Genom. 2008;9:75.

25. Huntemann M, Ivanova NN, Mavromatis M, Tripp HJ, PaezEspino D, Palaniappan K, et al. The standard operating procedure of the DOE-JGI, metagenome annotation pipeline (MAP v.4). Stand Genom Sci. 2015;10:86.

26. Meyer F, Goesmann A, McHardy AC, Bartels D, Bekel T, Clausen $\mathrm{J}$, et al. GenDB--an open source genome annotation system for prokaryote genomes. Nucleic Acids Res. 2003;31:2187-95.

27. Mann AJ, Hahnke RL, Huang S, Werner J, Xing P, Barbeyron T, et al. The genome of the alga-associated marine flavobacterium Formosa agariphila KMM $3901 \mathrm{~T}$ reveals a broad potential for degradation of algal polysaccharides. Appl Environ Microbiol. 2013;79:6813-22.

28. Finn RD, Bateman A, Clements J, Coggill P, Eberhardt RY, Eddy SR, et al. Pfam: the protein families database. Nucleic Acids Res. 2014;42:D222-30.

29. Yin Y, Mao X, Yang J, Chen X, Mao F, Xu Y. dbCAN: a web resource for automated carbohydrate-active enzyme annotation. Nucleic Acids Res. 2012;40:W445-51.

30. Altschul SF, Gish W, Miller W, Myers EW, Lipman DJ. Basic local alignment search tool. J Mol Biol. 1990;215:403-10.

31. Lombard V, Golaconda Ramulu H, Drula E, Coutinho PM, Henrissat B. The carbohydrate-active enzymes database (CAZy) in 2013. Nucleic Acids Res. 2014;42:D490-5.

32. Teeling H, Fuchs BM, Bennke CM, Krüger K, Chafee M, Kappelmann $\mathrm{L}$, et al. Recurring patterns in bacterioplankton dynamics during coastal spring algae blooms. eLife. 2016;5:e11888.

33. Barbeyron T, Brillet-Guéguen L, Carré W, Carrière C, Caron C, Czjzek M, et al. Matching the diversity of sulfated biomolecules: creation of a classification database for sulfatases reflecting their substrate specificity. PLoS ONE. 2016;11:e0164846.

34. Rawlings ND, Barrett AJ, Bateman A. MEROPS: the database of proteolytic enzymes, their substrates and inhibitors. Nucleic Acids Res. 2012;40:D343-50.

35. Hemsworth GR, Déjean G, Davies GJ, Brumer H. Learning from microbial strategies for polysaccharide degradation. Biochem Soc 
Trans. 2016;44:94-108.

36. Teeling H, Fuchs BM, Becher D, Klockow C, Gardebrecht A, Bennke CM, et al. Substrate-controlled succession of marine bacterioplankton populations induced by a phytoplankton bloom. Science. 2012;336:608-11.

37. Vizcaíno JA, Csordas A, Del-Toro N, Dianes JA, Griss J, Lavidas I, et al. 2016 update of the PRIDE database and its related tools. Nucleic Acids Res. 2016;44:11033.

38. Edgar RC. Search and clustering orders of magnitude faster than BLAST. Bioinformatics. 2010;26:2460-1.

39. Zhang Y, Wen Z, Washburn MP, Florens L. Refinements to label free proteome quantitation: how to deal with peptides shared by multiple proteins. Anal Chem. 2010;82:2272-81.

40. Katoh K, Standley DM. MAFFT multiple sequence alignment software version 7: improvements in performance and usability. Mol Biol Evol. 2013;30:772-80.

41. Price MN, Dehal PS, Arkin AP. FastTree 2--approximately maximum-likelihood trees for large alignments. PLoS ONE. 2010;5:e9490.

42. Labourel A, Jam M, Jeudy A, Hehemann JH, Czjzek M, Michel G. The beta-glucanase ZgLamA from Zobellia galactanivorans evolved a bent active site adapted for efficient degradation of algal laminarin. J Biol Chem. 2014;289:2027-42.

43. Labourel A, Jam M, Legentil L, Sylla B, Hehemann JH, Ferrières $\mathrm{V}$, et al. Structural and biochemical characterization of the laminarinase ZgLamCGH16 from Zobellia galactanivorans suggests preferred recognition of branched laminarin. Acta Cryst. 2015; D71:173-84.

44. Tamura K, Hemsworth GR, Déjean G, Rogers TE, Pudlo NA, Urs $\mathrm{K}$, et al. Molecular mechanism by which prominent human gut Bacteroidetes utilize mixed-linkage beta-glucans, major healthpromoting cereal polysaccharides. Cell Rep. 2017;21:2030.

45. Becker S, Scheffel A, Polz MF, Hehemann JH. Accurate quantification of laminarin in marine organic matter with enzymes from marine microbes. Appl Environ Microbiol. 2017;83:e03389-16.

46. Reese ET, Mandels M. Beta-D-1, 3 glucanases in fungi. Can J Microbiol. 1959;5:173-85.

47. Barras DR, Stone BA. Beta-1,3-glucan hydrolases from Euglena gracilis. II. Purification and properties of the beta-1,3-glucan exohydrolase. Biochim Biophys Acta. 1969;191:342-53.

48. Michel G, Barbeyron T, Kloareg B, Czjzek M. The family 6 carbohydrate-binding modules have coevolved with their appended catalytic modules toward similar substrate specificity. Glycobiology. 2009;19:615-23.

49. Gügi B, Le Costaouëc T, Burel C, Lerouge P, Helbert W, Bardor M. Diatom-specific oligosaccharide and polysaccharide structures help to unravel biosynthetic capabilities in diatoms. Mar Drugs. 2015;13:5993-6018.

50. Read SM, Currie G, Bacic A. Analysis of the structural heterogeneity of laminarin by electrospray-ionisation-mass spectrometry. Carbohydr Res. 1996;281:187-201.

51. Groisillier A, Labourel A, Michel G, Tonon T. The mannitol utilization system of the marine bacterium Zobellia galactanivorans. Appl Environ Microbiol. 2015;81:1799-812.

52. Gravot A, Dittami SM, Rousvoal S, Lugan R, Eggert A, Collén J, et al. Diurnal oscillations of metabolite abundances and gene analysis provide new insights into central metabolic processes of the brown alga Ectocarpus siliculosus. New Phytol. 2010;188:98-110.

53. Tonon T, Li Y, McQueen-Mason S. Mannitol biosynthesis in algae: more widespread and diverse than previously thought. New Phytol. 2017;213:1573-9.

54. Smith KA, Salyers AA. Characterization of a neopullulanase and an alpha-glucosidase from Bacteroides thetaiotaomicron 95-1. J Bacteriol. 1991;173:2962-8.
55. Kitamura M, Okuyama M, Tanzawa F, Mori H, Kitago Y, Watanabe N, et al. Structural and functional analysis of a glycoside hydrolase family 97 enzyme from Bacteroides thetaiotaomicron. J Biol Chem. 2008;283:36328-37.

56. Tuson HH, Foley MH, Koropatkin NM, Biteen JS. The starch utilization system assembles around stationary starch-binding proteins. Biophys J. 2018. https://doi.org/10.1016/j.bpj.2017.12. 015 .

57. Foley MH, Martens EC, Koropatkin NM. SusE facilitates starch uptake independent of starch binding in B. thetaiotaomicron. Mol Microbiol. 2018;108:551-66.

58. Fischer FG, Dörfel H. Die Polyuronsäuren der Braunalgen (Kohlenhydrate der Algen I). Hoppe-Seylers Z für Physiol Chem. 1955;302:186-203.

59. Ulaganathan T, Shi R, Yao D, Gu RX, Garron ML, Cherney M, et al. Conformational flexibility of PL12 family heparinases: structure and substrate specificity of heparinase III from Bacteroides thetaiotaomicron (BT4657). Glycobiology. 2017;27:176-87.

60. Arlov Ø, Aachmann FL, Sundan A, Espevik T, Skjåk-Bræk G. Heparin-like properties of sulfated alginates with defined sequences and sulfation degrees. Biomacromolecules. 2014;15:2744-50.

61. Mhanna R, Kashyap A, Palazzolo G, Vallmajo-Martin Q, Becher $\mathrm{J}$, Möller S, et al. Chondrocyte culture in three dimensional alginate sulfate hydrogels promotes proliferation while maintaining expression of chondrogenic markers. Tissue Eng Part A. 2014;20:1454-64.

62. Arlov $\emptyset$, Skjåk-Bræk G. Sulfated alginates as heparin analogues: a review of chemical and functional properties. Molecules. 2017;22:778.

63. Senoura T, Ito S, Taguchi H, Higa M, Hamada S, Matsui H, et al. New microbial mannan catabolic pathway that involves a novel mannosylglucose phosphorylase. Biochem Biophys Res Commun. 2011;408:701-6.

64. Cuskin F, Lowe EC, Temple MJ, Zhu Y, Cameron EA, Pudlo NA, et al. Human gut Bacteroidetes can utilize yeast mannan through a selfish mechanism. Nature. 2015;517:165-9.

65. Gómez-Pereira PR, Schüler M, Fuchs BM, Bennke C, Teeling H, Waldmann J, et al. Genomic content of uncultured Bacteroidetes from contrasting oceanic provinces in the North Atlantic Ocean. Environ Microbiol. 2012;14:52-66.

66. Wu J, Lv Y, Liu X, Zhao X, Jiao G, Tai W, et al. Structural study of sulfated fuco-oligosaccharide branched glucuronomannan from Kjellmaniella crassifolia by ESI-CID-MS/MS. J Carbohyd Chem. 2015;34:303-17.

67. Chiovitti A, Harper RE, Willis A, Bacic A, Mulvaney P, Wetherbee R. Variations in the substituted 3-linked mannans closely associated with the silicified walls of diatoms. J Phycol. 2005;41:1154-61.

68. Moreira LR, Filho EX. An overview of mannan structure and mannan-degrading enzyme systems. Appl Microbiol Biotechnol. 2008;79:165-78.

69. Ale MT, Mikkelsen JD, Meyer AS. Important determinants for fucoidan bioactivity: a critical review of structure-function relations and extraction methods for fucose-containing sulfated polysaccharides from brown seaweeds. Mar Drugs. 2011;9:2106-30.

70. Li B, Lu F, Wei X, Zhao R. Fucoidan: structure and bioactivity. Molecules. 2008;13:1671-95.

71. Sørensen I, Pettolino FA, Bacic A, Ralph J, Lu F, O’Neill MA, et al. The charophycean green algae provide insights into the early origins of plant cell walls. Plant J. 2011;68:201-11.

72. Painter TJ. Algal Polysaccharides. In: Aspinall GO, editor. The Polysaccharides. New York: Academic Press; 1983. p. 195-285. 
73. Wustman BA, Lind J, Wetherbee R, Gretz MR. Extracellular matrix assembly in diatoms (Bacillariophyceae). Iii. Organization Of fucoglucuronogalactans within the adhesive stalks of Achnanthes longipes. Plant Physiol. 1998;116:1431-41.

74. Murray A, Arnosti C, De La Rocha C, Grosart H-P, Passow U. Microbial dynamics in autotrophic and heterotrophic seawater mesocosms. II. Bacterioplankton community structure and hydrolytic enzyme activities. Aquat Microb Ecol. 2007;49:123-41.

75. Morris RM, Nunn BL, Frazar C, Goodlett DR, Ting YS, Rocap G. Comparative metaproteomics reveals ocean-scale shifts in microbial nutrient utilization and energy transduction. ISME J. 2010;4:673-85.
76. Williams TJ, Wilkins D, Long E, Evans F, DeMaere MZ, Raftery MJ, et al. The role of planktonic Flavobacteria in processing algal organic matter in coastal East Antarctica revealed using metagenomics and metaproteomics. Environ Microbiol. 2013;15:1302-17.

77. Myklestad SM. Production, chemical structure, metabolism, and biological function of the $(1 \rightarrow 3)$-linked, $\beta$-3-D-glucans in diatoms. Biol Oceanogr. 1989;6:313-26.

78. Alderkamp AC, van Rijssel M, Bolhuis H. Characterization of marine bacteria and the activity of their enzyme systems involved in degradation of the algal storage glucan laminarin. FEMS Microbiol Ecol. 2007;59:108-17.

\section{Affiliations}

\section{Lennart Kappelmann ${ }^{1} \cdot$ Karen Krüger $^{1} \cdot$ Jan-Hendrik Hehemann ${ }^{1,2} \cdot$ Jens Harder $^{1} \cdot$ Stephanie Markert ${ }^{3,4}$.} Frank Unfried $\mathbb{D}^{3,4} \cdot$ Dörte Becher $^{5} \cdot$ Nicole Shapiro $^{6} \cdot$ Thomas Schweder $\mathbb{D}^{3,4} \cdot$ Rudolf I. Amann ${ }^{1} \cdot$ Hanno Teeling ${ }^{1}$

1 Max Planck Institute for Marine Microbiology, Bremen, Germany

2 Zentrum für Marine Umweltwissenschaften, Bremen, Germany

3 Pharmaceutical Biotechnology, University Greifswald, Greifswald, Germany
4 Institute of Marine Biotechnology, Greifswald, Germany

5 Institute for Microbiology, University Greifswald, Greifswald, Germany

6 DOE Joint Genome Institute, Walnut Creek, CA, USA 